\title{
Research Letter \\ Synthesis of Hydroxyapatite by Interfacial Reaction in a Multiple Emulsion
}

\author{
Isao Kimura \\ Graduate School of Science and Technology, Niigata University, Ikarashi 2-8050, 950-2181 Niigata, Japan
}

Correspondence should be addressed to Isao Kimura, ikim@eng.niigata-u.ac.jp

Received 11 July 2007; Accepted 10 October 2007

Recommended by Yiu-Wing Mai

Interfacial reaction in a multiple emulsion, which is one of methods for producing inorganic microspheres, was applied to synthesize hydroxyapatite. The multiple emulsion was a W/O/W emulsion, made of dipotassium hydrogen phosphate solution as an inner aqueous phase, benzene as an oil phase, and calcium nitrate solution as an outer aqueous phase. The reaction was carried out in the multiple emulsion for 24 hours at $323 \mathrm{~K}$. The crystalline phase was varied with an initial $\mathrm{pH}$ of the inner aqueous phase, and single phase hydroxyapatite was synthesized at an initial $\mathrm{pH}$ of 12 . The products were composed of porous microspheres of less than $3 \mu \mathrm{m}$ in size. The microspheres were composed of nanospheres of less than $120 \mathrm{~nm}$ in size. By considering the mass balance, it was suggested that each nanosphere was formed in an inner aqueous phase droplet.

Copyright (c) 2007 Isao Kimura. This is an open access article distributed under the Creative Commons Attribution License, which permits unrestricted use, distribution, and reproduction in any medium, provided the original work is properly cited.

\section{INTRODUCTION}

Hydroxyapatite $\left(\mathrm{Ca}_{10}\left(\mathrm{PO}_{4}\right)_{6}(\mathrm{OH})_{2}\right.$, HAp) is a main inorganic constituent of hard tissues in the human body such as bones and teeth. Because of its intrinsic biocompatibility, applications as bioceramics have been studied since long time ago.

Actual bones are not a monolithic material made of the only HAp, but composites of HAp with collagen protein. The idea of mimicking natural state for improving the biocompatibility is reasonable. There are many reports on the preparation of composites of HAp nanoparticles with collagen or alternative polymer [1-9]. Composites with vitamins also seem to be effective for improving bone regeneration. In any case, it is easily predicted that nothing would succeed by merely mixing ingredients. For success in composite materials, it is generally required to homogeneously mix the ingredients and to prevent them separating. One of answers for such requirements is microencapsulation. Microcapsules are used for the preservation and controlled release of a core material, as well known. Therefore, microencapsulating an active component with HAp wall is thought to be meaningful.

In the most common procedure for producing microcapsules with an inorganic wall, inorganic hollow particles or porous microspheres are prepared. After that, they are impregnated with an active component, and then the wall is stuffed or covered with a suitable material. Hollow particles made of various substances have been produced by means of spray pyrolysis and interfacial reaction. Regarding HAp, many researchers adopt techniques that involve spraying raw material solutions [10-16]. On the other hand, interfacial reaction is carried out in a multiple emulsion [1720]. This method has a lot of advantages. A common stirred tank is sufficient to be used as the reactor, and therefore any special apparatus is unnecessary. Low synthesis temperatures around room temperature are usable, whereas spraying methods need relatively high temperature. In particular, it must be emphasized that when some active material is contained in the inner aqueous phase from the first, it can be directly microencapsulated with an inorganic wall material [18]. However, the synthesis of HAp by the interfacial reaction cannot be found in the literature. The purpose of this study is to confirm whether HAp microspheres can be prepared by this method.

\section{EXPERIMENTAL}

An inner aqueous phase was prepared by dissolving dipotassium hydrogen phosphate $\left(\mathrm{K}_{2} \mathrm{HPO}_{4}\right.$, special grade) at 
$0.3 \mathrm{~mol} / \mathrm{kg}$ in deionized and then distilled water, and adjusting the $\mathrm{pH}$ in the range of 9 to 12 with potassium hydroxide (KOH, special grade). Sorbitan monooleate (Span80, practical grade) as dispersion stabilizer for the inner aqueous phase was dissolved in benzene (special grade) at $200 \mathrm{~mol} / \mathrm{m}^{3}$ to prepare an oil phase. Calcium nitrate tetrahydrate $\left(\mathrm{Ca}\left(\mathrm{NO}_{3}\right)_{2} 4 \mathrm{H}_{2} \mathrm{O}\right.$, special grade) and polyoxyethylene(20) sorbitan monolaurate (Tween20, practical grade) as suspension stabilizer for the oil phase were dissolved in water at $0.5 \mathrm{~mol} / \mathrm{kg}$ and $10 \mathrm{~mol} / \mathrm{m}^{3}$ to prepare an outer aqueous phase. All of the reagents were supplied from Wako Pure Chemical Industries Ltd. (Osaka, Japan).

The inner aqueous phase of $40.5 \mathrm{~cm}^{3}$ and the oil phase of $94.5 \mathrm{~cm}^{3}$ were mixed and ultrasonicated for 30 minutes to prepare a $\mathrm{W} / \mathrm{O}$ emulsion. This emulsion was poured into the outer aqueous phase of $315 \mathrm{~cm}^{3}$ and stirred at $300 \mathrm{rpm}$ at $323 \mathrm{~K}$ and $300 \mathrm{rpm}$ to prepare a W/O/W emulsion. After 24 hours, the solid product was separated from the liquid phases with centrifugation. It was washed with benzene, ethanol, and water in turn. Finally, the products were obtained by freeze drying.

The crystalline phase was identified by X-ray powder diffraction (XRD). The morphology of the emulsion droplets and the final products was examined with an optical microscope (OM), a scanning electron microscope (SEM), and a transmission electron microscope (TEM). The yield $y$ was defined as a ratio of the total weight of the product to the theoretical weight of HAp based on the amount of $\mathrm{K}_{2} \mathrm{HPO}_{4}$ used.

\section{RESULTS AND DISCUSSION}

The droplets of the inner aqueous phase were so small that they could not be observed with an OM immediately after the preparation of the $\mathrm{W} / \mathrm{O}$ emulsion. This suggests that the initial size of the inner aqueous phase droplets was less than $1 \mu \mathrm{m}$, because the droplets of larger than $1 \mu \mathrm{m}$ were observable with the OM used. As time went on, the droplets of both inner aqueous phase and $\mathrm{W} / \mathrm{O}$ emulsion grew. The multiple emulsion was broken for 24 hours into two phases. The solid products were collected from the lower aqueous phase.

Figure 1 shows the powder X-ray diffraction patterns of the products. HAp was formed under any condition. Thus, it was confirmed that HAp is produced also by the interfacial reaction method. Monetite $\left(\mathrm{CaHPO}_{4}\right)$ has coexisted at initial $\mathrm{pH}$ values of 9 to 11 . In general, monetite is a dominant species for the solution syntheses at lower $\mathrm{pH}$ values. Riman et al. [21] have reported a phase diagram at $298 \mathrm{~K}$ under atmospheric pressure in the $\mathrm{CaO}-\mathrm{P}_{2} \mathrm{O}_{5}-\mathrm{NH}_{4} \mathrm{NO}_{3}-\mathrm{H}_{2} \mathrm{O}$ system as functions of precursor concentration and $\mathrm{pH}$. Suppose that the phase equilibria in the present system are similar to Riman's diagram, the results shown in Figure 1 can be explained as follows. The chemical reaction can be described as

$$
10 \mathrm{Ca}^{2+}+6 \mathrm{HPO}_{4}{ }^{2-}+2 \mathrm{OH}^{-} \longrightarrow \mathrm{Ca}_{10}\left(\mathrm{PO}_{4}\right)_{6}(\mathrm{OH})_{2}+6 \mathrm{H}^{+} .
$$

This equation means high $\mathrm{pH}$ values are essentially required to produce HAp. Since pH 9 is sufficiently high for the ex- periments in which the $\mathrm{pH}$ is kept constant, it can be thought that the only HAp is produced at the beginning of the synthesis under any condition of this study. The above equation also means that the $\mathrm{pH}$ steeply decreases as the reaction proceeds. At initial $\mathrm{pH}$ values of 9 to 11 , the $\mathrm{pH}$ in the inner aqueous phase may decrease to an area in which monetite is produced. Therefore, it is necessary for obtaining single-phase HAp to start at pH's high enough to keep standing in the HAp area during the synthesis process.

The yield of the product obtained at an initial $\mathrm{pH} 12$ was estimated to be $48 \%$. The exact extent of reaction should be larger than this value, because some loss at collection, separation, and drying is involved in it.

Most of the products were collected as agglomerates in irregular shape as shown in the OM micrograph of Figure 2(a). However, they seem to be composed of microspheres of less than $3 \mu \mathrm{m}$ size. This was confirmed by SEM observation as shown in Figure 2(b). Thus, it was found that HAp microspheres can be essentially prepared by the interfacial reaction in a multiple emulsion.

Figure 2(c) indicates that such a microsphere was composed of nanospheres of less than $120 \mathrm{~nm}$ size. The primary particles constituting the nanosphere are still finer, less than $30 \mathrm{~nm}$. These nanospheres seem to be porous. Therefore, it is expected to be usable as microcarriers or matrix-type microcapsules in the future.

The size of the microspheres will be estimated from the starting conditions to discuss the formation mechanism.

The amount of substance of $\mathrm{HPO}_{4}{ }^{2-}$ ion contained in an inner aqueous droplet with the diameter $d$ is

$$
\frac{\pi}{6} d^{3} C
$$

where $C$ is the molarity of $\mathrm{HPO}_{4}{ }^{2-}$. Six moles of $\mathrm{HPO}_{4}{ }^{2-}$ correspond to one mole of HAp. When $\mathrm{HPO}_{4}{ }^{2-}$ converts to HAp at a yield of $y$, the volume of HAp produced is

$$
\frac{\pi}{36} \frac{d^{3} C M_{\text {HAp }} y}{\rho_{\text {HAp }}},
$$

where $\rho_{\text {HAp }}$ is the true density of HAp and $M_{\text {HAp }}$ is the molar mass. The closest packing of spheres having the same size reveals the voidage to be $26 \%$. The voidage varies from $40 \%$ to $60 \%$ in a common state depending on the size, size distribution, and shape. If ultrafine HAp particles are agglomerated with the voidage $\varepsilon$ to form a nanosphere with the diameter $D_{\text {HAp }}$, the apparent volume of the sphere will be expressed by

$$
\frac{\pi}{6} D_{\mathrm{HAp}}^{3}=\frac{\pi}{36} \frac{d^{3} C M_{\mathrm{HAp}} y}{\rho_{\mathrm{HAp}} \varepsilon} .
$$

The molarity can be converted with the molality of $b$ and the density $\rho$ of $\mathrm{K}_{2} \mathrm{HPO}_{4}$ solution to

$$
C=\frac{b \rho}{b M_{\mathrm{HAp}}+1} .
$$

Hence, $D_{\text {HAp }}$ is found to be

$$
D_{\mathrm{HAp}}=\left(\frac{d^{3} M_{\mathrm{HAp}} y}{6 \rho_{\mathrm{HAp}} \varepsilon} \cdot \frac{b \rho}{b M_{\mathrm{HAp}}+1}\right)^{1 / 3} .
$$




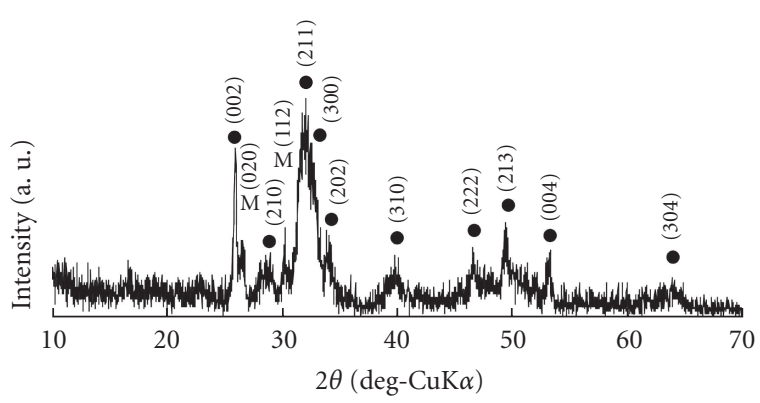

- HAp

M Monetite

(a)

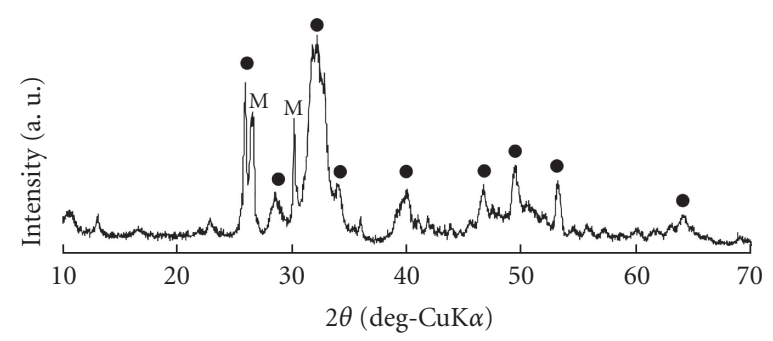

- HAp

M Monetite

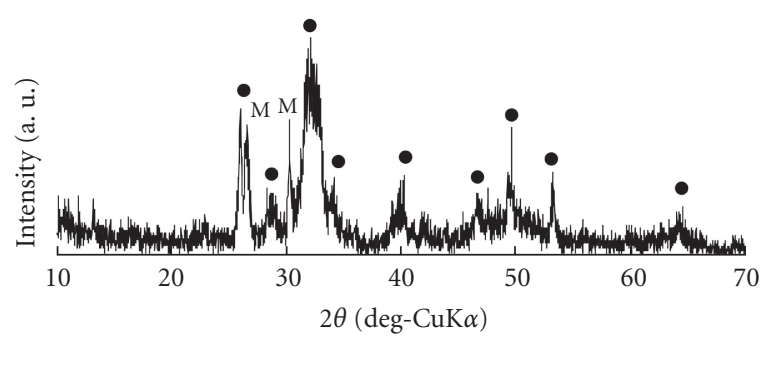

- HAp

M Monetite

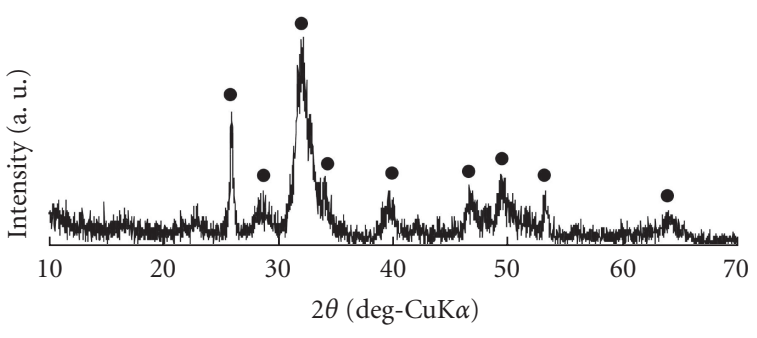

- HAp

(d)

FIgUre 1: Powder X-ray diffraction patterns of the products. Initial pH of the inner aqueous phase was (a) 9.0, (b) 10.0, (c) 11, and (d) 12. HAp and monetite were indexed as compared with JCPDS no. 9-432 and no. 9-80, respectively.

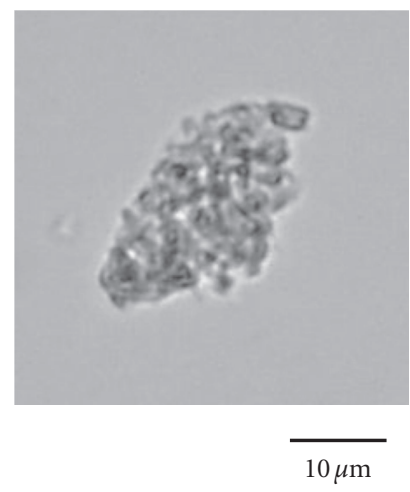

(a)

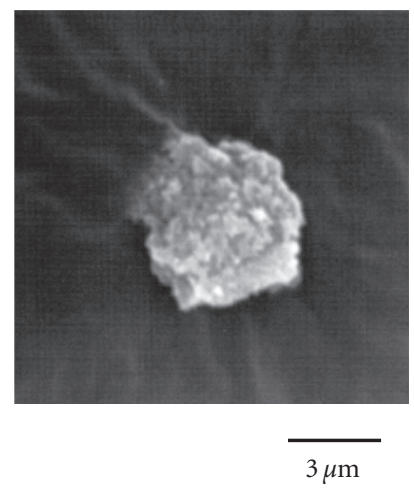

(b)

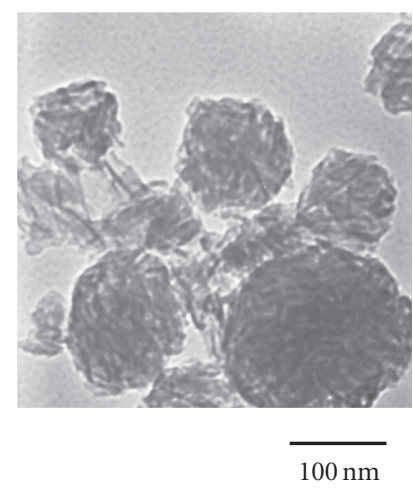

(c)

FIgure 2: Morphologies of HAp produced at an initial pH of 12. (a) Optical micrograph, (b) SEM micrograph, and (c) TEM micrograph.

Suppose respective values as $d=500 \mathrm{~nm}, y=48 \%$, and $\varepsilon=0.5$, and assign $\rho_{\text {HAp }}=3.16 \mathrm{~g} / \mathrm{cm}^{3}, b=0.3 \mathrm{~mol} / \mathrm{kg}, \rho=1.05 \mathrm{~g} / \mathrm{cm}^{3}$, and $M_{\text {HAp }}=1004 \mathrm{~g} / \mathrm{mol}$, then the diameter of the HAp microsphere is estimated to be $115 \mathrm{~nm}$. This value is not inconsistent with the result shown in Figure 2(c). Therefore, it is suggested that the multiple emulsion had been sustained at least until HAp microspheres were formed.

From the results shown so far, the formation mechanism of HAp microspheres can be inferred as follows. At step 1, calcium ion in the outer aqueous phase diffuses through the oil phase to the interface between the oil phase and the inner aqueous phase. At step 2, calcium ion reacts at the interface with hydrogen phosphate ion to produce primary, ultrafine HAp particles. At step 3, the ultrafine HAp particles are transported from the interface to the inside of the inner aqueous phase droplet. At step 4, they agglomerate to form nanospheres as shown in Figure 2(c). At step 5, the inner aqueous phase droplets coalesce each other and 
the nanospheres coagulate to form microspheres as shown in Figure 2(b). Finally, they escape from the W/O emulsion droplet to the continuous phase.

The products in the form of discrete microspheres must be necessary for practical applications as microcarriers. For that purpose, the agglomeration at step 5 should be avoided. The multiple emulsion formed in this study was not yet recognized to be sufficiently stable. As stated above, the droplets of both phases grew as time went on. In general, the stability of droplets is altered according to the raw material species, concentration, and $\mathrm{pH}$ of the solutions, temperature, and coexisting species, for example, surfactants. More detailed investigation is necessary to find out the optimum condition, under which much higher stability is achieved.

\section{CONCLUSIONS}

Interfacial reaction in a multiple emulsion was applied to synthesize HAp, and it was confirmed that HAp can be produced by this method. The products were HAp microspheres agglomerated. Each microsphere was constituted by a few hundred nanometer-sized porous spheres, composed of primary nanoparticles. The morphology of the microspheres lets us expect that they will be applied to microcarriers for drug delivery system and scaffolds for the regenerative medicine in the future.

\section{ACKNOWLEDGMENTS}

A part of this study was financially supported by Grant-inAid for Scientific Research (C) no. 18560666, Japan Society for the Promotion of Science, and a grant for Promotion of Niigata University Research Projects, 2006. The author appreciates Mr. K. Iwafune of Center for Instrumental Analysis, Niigata University, for X-ray diffraction analysis, Mr. N. Saito of Faculty of Engineering, Niigata University, for TEM observation, and Mr. Y. Sayama of Faculty of Engineering, Niigata University, for his effort in experiments.

\section{REFERENCES}

[1] F. Y. Hsu, S.-C. Chueh, and Y. J. Wang, "Microspheres of hydroxyapatite/reconstituted collagen as supports for osteoblast cell growth," Biomaterials, vol. 20, no. 20, pp. 1931-1936, 1999.

[2] M. Kikuchi, S. Itoh, S. Ichinose, K. Shinomiya, and J. Tanaka, "Self-organization mechanism in a bone-like hydroxyapatite/collagen nanocomposite synthesized in vitro and its biological reaction in vivo," Biomaterials, vol. 22, no. 13, pp. 1705-1711, 2001.

[3] N. Roveri, G. Falini, M. C. Sidoti, et al., "Biologically inspired growth of hydroxyapatite nanocrystals inside self-assembled collagen fibers," Materials Science and Engineering C, vol. 23, no. 3, pp. 441-446, 2003.

[4] R. Murugan and S. Ramakrishna, "Bioresorbable composite bone paste using polysaccharide based nano hydroxyapatite," Biomaterials, vol. 25, no. 17, pp. 3829-3835, 2004.

[5] D. Lickorish, J. A. M. Ramshaw, J. A. Werkmeister, V. Glattauer, and C. R. Howlett, "Collagen-hydroxyapatite composite prepared by biomimetic process," Journal of Biomedical Materials Research A, vol. 68, no. 1, pp. 19-27, 2004.
[6] L. Fang, Y. Leng, and P. Gao, "Processing of hydroxyapatite reinforced ultrahigh molecular weight polyethylene for biomedical applications," Biomaterials, vol. 26, no. 17, pp. 3471-3478, 2005.

[7] L. Hong, Y. L. Wang, S. R. Jia, Y. Huang, C. Gao, and Y. Z. Wan, "Hydroxyapatite/bacterial cellulose composites synthesized via a biomimetic route," Materials Letters, vol. 60, no. 1314, pp. 1710-1713, 2006.

[8] Y. Zhai and F. Z. Cui, "Recombinant human-like collagen directed growth of hydroxyapatite nanocrystals," Journal of Crystal Growth, vol. 291, no. 1, pp. 202-206, 2006.

[9] Y. Z. Wan, L. Hong, S. R. Jia, et al., "Synthesis and characterization of hydroxyapatite-bacterial cellulose nanocomposites," Composites Science and Technology, vol. 66, no. 11-12, pp. 1825-1832, 2006.

[10] P. Luo and T. G. Nieh, "Preparing hydroxyapatite powders with controlled morphology," Biomaterials, vol. 17, no. 20, pp. 1959-1964, 1996.

[11] T. Akazawa, M. Kobayashi, and K. Kodaira, "A newly designed adsorbent prepared from hydroxyapatite originating from cattle-bones for chromatographic separation of albumin and lysozyme," Bulletin of the Chemical Society of Japan, vol. 70, no. 9, pp. 2323-2329, 1997.

[12] R.-X. Sun, Y.-P. Lu, M.-S. Li, S.-T. Li, and R.-F. Zhu, "Characterization of hydroxyapatite particles plasma-sprayed into water," Surface and Coatings Technology, vol. 190, no. 2-3, pp. 281-286, 2005.

[13] J. L. Xu, K. A. Khor, Y. W. Gu, R. Kumar, and P. Cheang, "Radio frequency (rf) plasma spheroidized HA powders: powder characterization and spark plasma sintering behavior," Biomaterials, vol. 26, no. 15, pp. 2197-2207, 2005.

[14] S. Dyshlovenko, L. Pawlowski, P. Roussel, D. Murano, and A. Le Maguer, "Relationship between plasma spray operational parameters and microstructure of hydroxyapatite coatings and powder particles sprayed into water," Surface and Coatings Technology, vol. 200, no. 12-13, pp. 3845-3855, 2006.

[15] R. Sun, M. Li, Y. Lu, and S. Li, "Dissolution behavior of hollow hydroxyapatite microspheres immersed in deionized water," Materials Research Bulletin, vol. 41, no. 6, pp. 1138-1145, 2006.

[16] Q. Wang, W. Huang, D. Wang, B. W. Darvell, D. E. Day, and M. N. Rahaman, "Preparation of hollow hydroxyapatite microspheres," Journal of Materials Science: Materials in Medicine, vol. 17, no. 7, pp. 641-646, 2006.

[17] K. Miyata and Y. Nakahara, "The preparation of inorganic particles by interfacial reaction," Progress in Organic Coatings, vol. 5, no. 2, pp. 115-129, 1977.

[18] I. Kimura, S. Ikarashi, N. Saito, and M. Tanaka, "Microencapsulation of thermal-sensitive pigment with inorganic wall material by interfacial reaction in multiple dispersion," Advanced Powder Technology, vol. 8, no. 1, pp. 1-13, 1997.

[19] M. Fujiwara, K. Shiokawa, Y. Tanaka, and Y. Nakahara, "Preparation and formation mechanism of silica microcapsules (hollow sphere) by water/oil/water interfacial reaction," Chemistry of Materials, vol. 16, no. 25, pp. 5420-5426, 2004.

[20] I. Morishige, E. Toorisaka, M. Hirata, T. Ohtake, and T. Hano, "Preparation of various metal-silicate micro-balloons using W/O/W emulsion," Journal of Microencapsulation, vol. 22, no. 3, pp. 291-301, 2005.

[21] R. E. Riman, W. L. Suchanek, K. Byrappa, C.-W. Chen, P. Shuk, and C. S. Oakes, "Solution synthesis of hydroxyapatite designer particulates," Solid State Ionics, vol. 151, no. 1-4, pp. 393-402, 2002. 

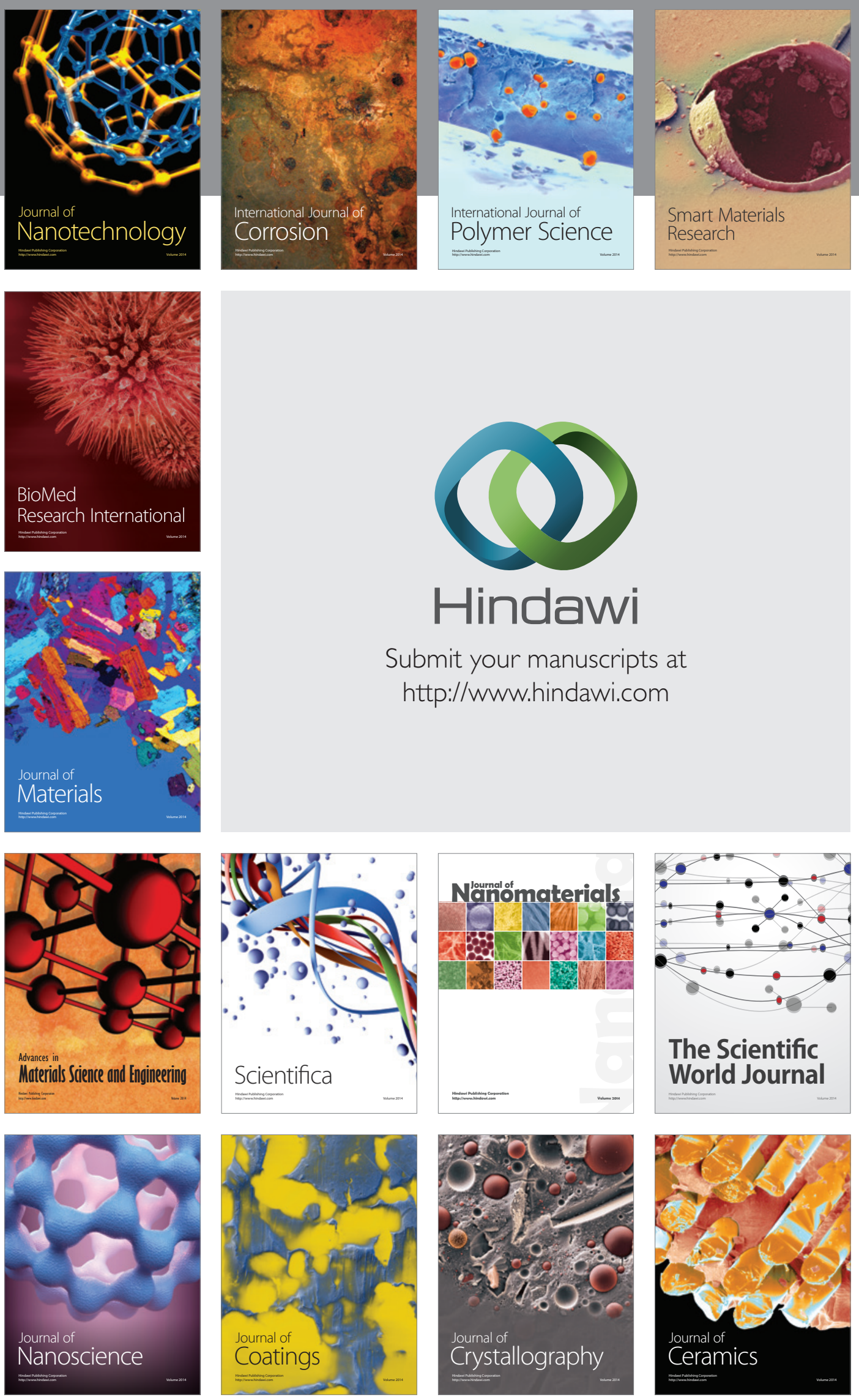

The Scientific World Journal

Submit your manuscripts at

http://www.hindawi.com

\section{World Journal}

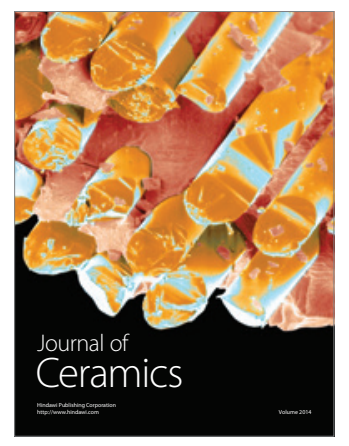

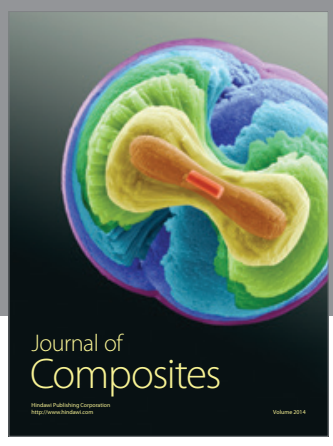
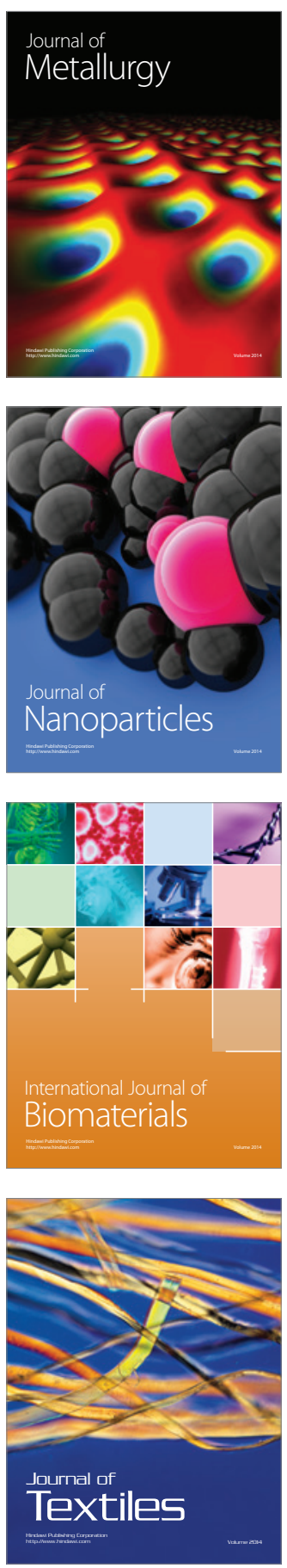